\title{
A PRODUÇÃO DE SENTIDO PESSOAL PARA O EXERCÍCIO DA DOCÊNCIA NO PERCURSO FORMATIVO DE UMA ESTUDANTE DE PEDAGOGIA
}

\author{
Adriana Ofretorio de Oliveira Martin Martinez ${ }^{1}$ \\ Anna Regina Lanner de Moura²
}

\begin{abstract}
RESUMO
Propomos, neste artigo, discutir a produção de sentido pessoal para a docência de uma estudante de Pedagogia (Estudante P) quando participou da disciplina de Estágio Supervisionado que compôs, ao longo de um ano letivo, com outras disciplinas do curso - o Projeto Integrado (um projeto de integração disciplinar) - de uma universidade pública. Esse Projeto solicitou aos estudantes de Pedagogia a realização de tarefas formativas, dentre elas a escrita de quatro narrativas reflexivas, que, com as falas de uma entrevista com os estudantes, compôs o corpus da pesquisa de Mestrado na qual referenciamos este artigo. Da análise das narrativas e da entrevista da Estudante $P$, foi possível observar, pelo aporte da teoria da Atividade de Leontiev (2004), que a produção dos sentidos pessoais estava relacionada às problematizações que a estudante fez das experiências vividas no exercício da docência no estágio, na elaboração, na realização do projeto de ensino e nas relações estabelecidas entre colegas e professores. Foi também possível conjecturar que a escrita narrativa se constituiu um modo de tomada de consciência, pela estudante, do caráter formativo das atividades realizadas durante sua participação no Projeto.
\end{abstract}

Palavras-chave: Sentido pessoal. Formação de professores. Estágio supervisionado. Teoria da atividade.

\section{THE PRODUCTION OF PERSONAL SENSE FOR THE EXERCISE OF TEACHING} IN THE COURSE OF FORMATION FOR A STUDENT OF PEDAGOGY

\begin{abstract}
We propose in this article to discuss the production of personal sense to the teaching in a student of Pedagogy (Student P) when she participated, during a school year, along with other disciplines of the course in the supervised training discipline that composed, the Integrated Project (a disciplinary integration project) of an public university. This Project requested to students of Pedagogy the realization of formatives tasks, among them, the writting of four reflexives narratives, which with the speeches of interviews with students, composed the data of the master's research we referenced in this article. Fromthe Students' P interview and narrative analyses, it was possible to observe, in light of Leontiev's activity theory (2004), that the personal sense productions was related to the problematization that this student made of herlived experiences in the training exercise of teaching, in the project design and its implementation and in the relationships established between peers and teachers. It was also possible to conjecture that narrative writting constituted a mode of awareness, by the student, of the formative character of the activities perfomed during her participation in the Project
\end{abstract}

Keywords: Personal sense. Teacher education. Supervised training. Activity theory.

RECEBIDO EM: 30/8/2019

ACEITO EM: 23/10/2019

\footnotetext{
${ }^{1}$ Graduação em Pedagogia pela Universidade de São Paulo (2006). Mestrado em Educação pela Faculdade de Educação da Unicamp (2010), na área de Ensino e Práticas Culturais. Doutoranda no curso de Pós-Graduação em Psicologia e Educação da Faculdade de Educação da Unicamp, vinculada ao grupo de pesquisa Pensamento e Linguagem (GPPL). http://lattes.cnpq.br/7102298094954897. http://orcid.org/00000002-6870-371X. aofretorio@gmail.com

${ }^{2}$ Licenciatura em Física pela Universidade do Vale do Rio dos Sinos (Unisinos-RS, 1974), Mestrado em Educação (1983), Doutorado em Educação (1995) e Livre Docência (2015) pela Universidade Estadual de Campinas (Unicamp-SP). Tem vínculo institucional com a Universidade Ceuma-Uniceuma de São Luís do Maranhão. Participa, também, na qualidade de Docente Permanente e de orientadora, do Programa de Pós-Graduação de Educação em Ciências e Matemática (PPGECEM) da Rede Amazônica de Educação em Ciências e Matemática (Reamec/Uniceuma), atuando na linha de pesquisa Formação de professores para a Educação em Ciências e Matemática, com enfoque na temática Educação, Linguagem e Práticas Culturais, incluindo nessas, as práticas escolares. http://lattes.cnpq.br/7828069698398308. https://orcid.org/0000-0003-3595-2151. lanner4@gmail.com
} 
Este artigo ancora-se em informações de nosso banco de dados - especificamente dos procedimentos metodológicos e da análise de uma pesquisa ${ }^{3}$ desenvolvida no contexto da formação inicial do curso de Pedagogia de uma universidade pública paulista, cujo foco foi a formação para a docência na disciplina de Estágio Supervisionado. Tal disciplina, no período da referida investigação, compunha, com outras três oferecidas pelo curso (Prática pedagógica, Fundamentos do ensino de Matemática e Fundamentos do ensino de Ciências), um projeto de integração disciplinar intitulado "Projeto Integrado", que era desenvolvido pelos docentes das quatro disciplinas.

A forma integrada do trabalho pedagógico de formação tinha como objetivo proporcionar aos estudantes uma vivência teórico-prática do ato de ensinar. Além disso, preconizava que esses futuros professores vivenciassem situações reais de ensino e que, a partir delas, formulassem questionamentos sobre seu processo de formação durante a vivência das atividades do Projeto Integrado.

Os docentes, de comum acordo com os estudantes e orientados pelo planejamento didático-pedagógico do Projeto, propuseram a realização das seguintes atividades de formação: seminários de adensamento teórico; elaboração de um projeto de ensino em grupos temáticos, cujas atividades integravam os conteúdos de Ciências e Matemática, visando o desenvolvimento dessas na escola-campo de realização do estágio; a produção da escrita de quatro narrativas reflexivas; e a elaboração de um portfólio reflexivo. As narrativas deveriam ter como eixo de reflexão o próprio processo de formação ao longo das quatro disciplinas. O portfólio, por sua vez, deveria ilustrar todo este percurso.

A integração disciplinar, promovida pelo Projeto Integrado, teve a duração de dois semestres seguidos - no terceiro ano do curso de Pedagogia -, e todas as atividades formativas desse período foram planejadas e discutidas com os estudantes no início de cada disciplina do Projeto. A execução dessas atividades demandou orientações contínuas dos docentes responsáveis pelo Projeto, como a indicação de leituras que dessem suporte aos seminários de adensamento teórico e orientações específicas sobre a elaboração dos projetos de ensino de Matemática e Ciências e para a escrita das narrativas.

Com o objetivo de propor aos estudantes as narrativas como ponto alto da reflexão sobre a própria formação, foi instituído o Fórum das Narrativas, que ocorria mensalmente e era pautado na leitura e na discussão em grupo das narrativas discentes e docentes. As narrativas docentes eram escritas a partir da leitura das narrativas discentes, com o objetivo de trazer à reflexão coletiva do Fórum as problematizações, naquelas expressas, sobre a formação para a docência.

Por se tratar de um contexto singular de formação do futuro professor, o Projeto de Integração disciplinar foi locus de investigação de algumas pesquisas na área da educação e de produção de conhecimento sobre esse modo integrado de formação docente, sustentado pelo olhar problematizador e reflexivo da realização das atividades nele propostas (NAKAMURA, 2014; UNTALER, 2011). Dentre essas investigações, encontra-se a pesquisa de Mestrado 4 que realizamos e na qual este artigo referencia-se.

\footnotetext{
3 Parecer CEP no 043/2009, CAAE:0032.0.146.000-09. Educadores (2011) e no 18으 Cole - Congresso de Leitura do Brasil (2012).

${ }^{4}$ Foram feitas apresentações desta pesquisa em dois eventos: no XI Congresso Estadual Paulista de Formação de 
Partindo do pressuposto de que os estudantes expressariam em suas narrativas reflexivas significados pessoais de sua formação para a prática docente no âmbito do Projeto Integrado e, especificamente, no contexto do estágio, nossa investigação foi orientada pela seguinte questão: "É possível que estudantes de Pedagogia, quando realizam tarefas relacionadas à prática de ensino no contexto da disciplina de Estágio Supervisionado, vinculado a um projeto coletivo de formação, produzam sentidos pessoais de formação para a docência? Quais seriam e como são produzidos esses sentidos?"

Dentre as produções dos estudantes, no contexto do Projeto, escolhemos as narrativas como dados empíricos da investigação com base na hipótese de que, nessas produções escritas, apareceriam as reflexões dos estudantes estagiários tanto sobre a atividade de elaboração do projeto de ensino de Ciências e Matemática - que demandou ações como o estudo e pesquisa sobre atividades de sala de aula que propusessem situações-problema integradoras dessas duas áreas -, quanto sobre sua aplicação no exercício docente do estágio.

Ademais, a pesquisa mencionada ancorou-se na potencialidade da narrativa reflexiva como um meio de expressão e, ao mesmo tempo, de produção de sentidos pessoais, na perspectiva leontieviana. Supôs-se que, ao narrar reflexivamente o próprio processo de formação no interior do Projeto Integrado, os estudantes estariam produzindo significados pessoais sobre suas experiências formativas nas atividades do Projeto e que seria possível que ocorressem também narrativas não demonstrativas de sentidos pessoais. "Assim, a palavra se tornaria o instrumento de veiculação de sentidos" (VYGOTSKY, 2008, p. 181), dada a experiência individual de cada estudante.

É importante destacar que nossa investigação (MARTIN, 2010) baseou-se na trajetória formativa de quatro estudantes mulheres que participaram do Projeto Integrado, selecionadas de modo a obter duas duplas participantes de grupos temáticos diferentes do projeto de ensino. No processo de investigação, a metodologia de estudo, ou seja, a busca por indícios, dos sentidos pessoais sobre a própria formação docente, produzidos pelas estudantes na acepção de Ginzburg (2013), e a análise da produção do sentido pessoal para a docência dos estudantes, com base nos estudos de Leontiev (2004), fez com que escolhêssemos analisar apenas a trajetória formativa de quatro estudantes. Isso resultou na leitura e aprofundamento analítico das quatro narrativas produzidas por elas, totalizando 16 narrativas, além das demais tarefas, como projetos de ensino e portfólios.

Para compor, com as narrativas, o corpus da pesquisa, nos valemos de uma entrevista semiestruturada, realizada no momento final da execução do Projeto Integrado, com os grupos temáticos do projeto de ensino, no qual estavam inseridas as estudantes que optaram por participar da investigação.

Para este artigo escolhemos discutir a produção de sentidos nas quatro narrativas de uma das quatro estudantes que participaram da pesquisa, por considerarmos que as reflexões sobre sua trajetória formativa representam a totalidade do contexto formativo do Projeto Integrado. 


\section{O ESTÁGIO SUPERVISIONADO COMO CONTEXTO DE POSSIBILIDADES FORMATIVAS}

No contexto de formação de um curso de Licenciatura, especificamente o de Pedagogia, é comum ouvirmos dos estudantes relatos impactantes sobre as experiências no campo do estágio quando iniciam suas observações e intervenções nas escolas. Algumas dessas experiências os afetam de modo que os levam a questionar a escolha do curso e até mesmo a decisão pela carreira docente. Isso nos indica que a vivência no estágio docente é uma experiência tensional, que provoca e promove sentidos sobre ser professor.

Além dessas informações, encontramos, em muitas pesquisas da área (GUEDES-PINTO, FONTANA, 2006; MARTINS, 2009; PIMENTA; GHEDIN, 2008; ZABALZA, 2014), a afirmação de que as experiências de formação docente podem ser redimensionadas pelo contexto mediador da disciplina de estágios, ou seja, que a capacitação acadêmica assume um papel primordial no processo de formação do futuro professor. Isso é possível, pois é nos diálogos elaborados no contexto do estágio que se pode problematizar, refletir e ampliar as implicações do exercício do ensino na trajetória formativa para a docência para cada estudante estagiário.

Muitos projetos ${ }^{5}$ que incentivam práticas de estágio, porém, estão no limiar de aceitação de uma conjuntura econômica empresarial no contexto educacional - isto é, de formação apenas técnica e sistematizada para as exigências de um mercado de trabalho -, o que descaracteriza o papel primordial do estágio para a formação do futuro professor (PIMENTA, 2017), que também passa pela elaboração de um senso crítico sobre a realidade educacional do país. Por isso, é importante planejar e realizar, no campo do estágio, estratégias que visem à problematização das experiências e das possibilidades de formação para a docência, relacionando a realidade vivida da escola com fatores sociais, econômicos e políticos, e com destaque para o professor enquanto um agente de potencial transformação das relações perniciosas de poder que a escola pode vir a reproduzir (ZEICHNER, 2008).

Desse modo, a relação entre teoria e prática, tão solicitada nos contextos de formação inicial do docente (PIMENTA; LIMA, 2011), ancora-se em diálogos da práxis, ou seja, de ações intencionais de compreensão e intervenção na realidade escolar. Define-se, assim, a ação do professor como possibilidade de (re)inventar o cotidiano, descobrindo os sentidos que o constitui e problematizando-os à medida que esses compõem a experiência individual e coletiva de cada estudante de Licenciatura.

Outra questão relevante a respeito da formação inicial é a uniformidade das propostas de formação de professores, orientadas por documentos oficiais, como leis, diretrizes e resoluções (BRASIL, 1997, 2011, 2016), sempre formuladas para uma padronização dessa oportunidade. Trata-se, em certo ponto, de um avanço, mas que pode enrijecer as ações formadoras se desconsiderar as condições concretas de formação de cada região do país. É desejável oportunizar as mesmas condições de formações para

\footnotetext{
${ }^{5}$ Nesse âmbito, destacamos projetos formativos como o Pibid, organizado a partir de uma rede de apoio ao estudante, que escolhe, por meio dele, inserir-se no campo escola como estagiário. 
os professores, porém não se pode desconsiderar as especificidades e necessidades de cada localidade brasileira. É diante dessa questão que a articulação entre teoria e prática promove o olhar atento para as singularidades educacionais, pois um modo de planejar a prática docente não pode ser concebido como uma receita, mas como oportunidade de adequação às necessidades que as relações de ensino apresentam ao professor, considerando quão diferentes são os sujeitos que compõem esse contexto.

O Estado, assumindo o seu papel de legislador, sustenta propostas curriculares similares para os cursos de Licenciatura de diferentes universidades. Mesmo a efemeridade de algumas propostas governamentais, todavia, não impede a autonomia das universidades no desenvolvimento de modos outros de articulação entre a teoria e a prática; melhor dizendo, em ações formativas que relacionam o contexto real das escolas da localidade com os diálogos promulgados sobre o ensinar, em contextos de formação docente nos quais a pluralidade de concepções de ensino possa ser problematizada.

Historicamente, a formação docente passou por mudanças substanciais: a noção técnica para uma ação avaliativa e analítica do professor deu lugar à concepção de professor reflexivo, inicialmente proposta por Shön (2000) e debatida por muitos outros pesquisadores (PIMENTA, 2008; ZEICHNER, 1993, 2008). Mesmo com críticas, essa proposta alavancou a possibilidade de novas práticas de formação de professores, tornando ainda mais fecunda a problematização de uma práxis docente, quando dimensiona a reflexão como ação constituinte das ações dos professores. É revelado, ainda, um processo de desenvolvimento profissional que não se limita apenas à experiência vivida, mas a redimensiona, dando-lhe novos sentidos, novos fazeres.

As muitas investigações acadêmicas que surgiram nessa vertente - tais como as de Alarcão (2010), Aragão, Nasciutti e Affonso (2017), Barolli, Moura e Prado (2008), Pimenta $(2002,2008)$ e Sá-Chaves (2004), entre outros - possibilitaram-nos compreender novas dimensões da relação reflexão e prática docente, pois a produção sobre o campo educacional descola-se da ênfase no conhecimento acadêmico para o sujeito professor, o qual "[é] o profissional que produz conhecimento, problematiza e modifica sua prática e sua realidade" (ARAGÃO; NASCIUTTI; AFFONSO, 2017, p. 248). Nesse contexto, surgem instrumentos outros de formação docente, por meio dos quais a experiência é organizada e meta-analisada - como é o caso, por exemplo, dos portfólios de formação, memoriais, inventários pedagógicos e da própria narrativa reflexiva (PRADO; FERREIRA, 2011).

Promulgar, então, instrumentos que fomentam esse modo de problematizar as experiências dos professores, principalmente nos cursos de formação inicial, é um modo de valorizar a prática desses profissionais e toda a potencialidade de produção de conhecimento sobre o ensino que ela carrega. Com isso, a disciplina de Estágio Supervisionado torna-se um contexto privilegiado de formação, pois nela inicia-se a articulação entre conhecimento teórico e prático na docência para o estudante de Pedagogia.

A partir dessa perspectiva, entende-se que as atividades propostas pelo Projeto Integrado - cujo mote foi a intencionalidade de uma formação crítica e articuladora entre teoria e prática que envolvesse a disciplina de Estágio Supervisionado e as ações no campo do estágio - podem ser consideradas fontes de reflexão do fazer docente, e, supostamente, também, fontes de produção de sentido pessoal sobre a docência dos estudantes-estagiários, futuros professores. 


\section{ATIVIDADE PRÁTICA DOCENTE E PRODUÇÃO DE SENTIDOS: Um Olhar Fundamentado em Leontiev}

Voltar a atenção para o campo de realização do estágio supervisionado como contexto de formação, remeteu-nos a duas temáticas conceituais que tangenciam a formação de professores: o aprendizado de práticas docentes, que se relacionam às ações objetivas, e a produção de sentidos sobre a profissão, que se referem às ações subjetivas do professor.

As ações objetivas, ligadas à prática de ensino propriamente dita, constituem-se pelo planejamento das aulas no que se diz respeito às estratégias de ensino, os materiais utilizados, o conteúdo a ser ensinado e o método de avaliação. As ações subjetivas, por sua vez, são impulsionadoras de motivos e necessidades próprias do docente; aquelas em cujo âmbito estariam sendo produzidos os sentidos pessoais, e que, portanto, entram como elemento preponderante no processo do exercício docente do planejamento, dando particularidade a cada ação no contexto da sala de aula. Assim, o desenvolvimento das atividades, enquanto produto final dos planos de ações, passa, inevitavelmente, pelas concepções pessoais dos professores acerca do próprio trabalho, tal como acerca do ensino e aprendizagem. Nesse sentido, ocorre uma modelagem dos objetivos à luz da singularidade de cada profissional, uma vez que a prática do professor é uma ação relacional, ou seja, produzida na/pela relação com seus alunos e demais atores de uma instituição escolar. É uma ação que pode se tornar práxis, à medida que transgrida a reprodução de práticas e abarque ações transformadoras da realidade.

Com relação a segunda temática - produção de sentidos sobre a profissão, referente à reflexão sobre a experiência no campo do estágio -, a pesquisa reporta-se aos estudos de Leontiev $(1983,2004)$ sobre a produção de sentido pessoal pelo sujeito quando está em atividade. Para o autor, o conceito de sentido pessoal une-se estritamente a outro conceito de sua teoria: o de atividade.

O autor comenta que a realidade objetiva está em constante modificação pelas ações humanas, e que essas ações, por conseguinte, produzem as atividades mentais. O ser humano é um ser moldado aos significados sociais e culturais, fruto de sua ação no meio. Em uma relação constante, o homem produz sentidos pessoais quando se apropria e internaliza significados sociais existentes sobre uma ação, o que ocorre pela mediação de instrumentos em ações objetivas, impulsionadas por determinados motivos. A mediação pode ocorrer por meio de objetos concretos (instrumentos) ou por um sistema simbólico (signos), ao qual, na sua criação, são atribuídos sentidos de uso e existência. Foi defendendo essa perspectiva de desenvolvimento humano que Leontiev $(1983,2004)$ desenvolveu os conceitos que compõem a teoria da atividade. Para o autor, a atividade é o campo de manifestações e modificações das ações psíquicas que acontecem em determinadas condições. O ser humano pode gerar ações ou atividades quando age no ambiente sociocultural, produzindo ou não outros sentidos. A diferença entre atividade e ação está no processo que, quando relacionado à atividade, sempre produzirá um sentido pessoal no sujeito que a realiza. Isso porque a ela está intrínseco 
um motivo pessoal ou necessidade de realização definido como o objeto final dessa ação. Já a ação propriamente dita pode ser realizada sem que o sujeito produza sentido pessoal, ou seja, sem que esteja em atividade.

[...] a primeira condição de toda atividade é a necessidade. Todavia, em si, a necessidade não pode determinar a orientação concreta de uma atividade, pois é apenas no objeto da atividade que ela encontra a sua determinação: deve, por assim dizer, encontrar-se nele. Uma vez que a necessidade encontra a sua determinação no objeto (se "objetiva" nele), o dito objeto torna-se motivo da atividade, aquilo que o estimula (LEONTIEV, 2004, p. 115).

Todo processo de atividade é uma ação, mas nem toda ação é considerada um processo de atividade, pois as ações de um mesmo sujeito em um determinado contexto podem ter ou não intenções objetivas (LEONTIEV, 2004). As intenções objetivas engendram uma ação consciente e produtora de sentidos pessoais; elaboram um processo de atividade porque o motivo da ação coincide com o seu fim, e isso afeta, constitui e modifica a psique e o comportamento do sujeito. Já as ações não objetivas - ou seja, que não são oriundas de um motivo ou necessidade fim - produzem sentidos que não necessariamente afetam a consciência do sujeito.

Assim, produzir sentido pessoal une-se estritamente a estar em atividade, e estar em atividade conduz a uma modificação do significado social atribuído a ela. Isto é, no processo de atividade, o sujeito internaliza o significado social e, por ele, produz outro significado, definido como sentido pessoal. Dessa forma, ao mesmo tempo que contém o primeiro, o sentido pessoal é um pensamento que difere do significado por sua qualidade singular e relação direta com o motivo da ação.

Um exemplo disso pode ser o modo como é desenvolvido o registro das atividades diárias que um professor realiza ao final de um dia letivo. A escrita pode ser meramente descritiva e/ou obrigatória, quando assumida como uma tarefa que faz parte de suas funções como professor. Se, porém, esse momento de escrever tem um motivo que o sustenta - como problematizar uma atividade realizada com as crianças -, tal exercício passa a ter outro significado para esse professor, um sentido singular, que se relaciona à sua necessidade em questionar o vivenciado e projetar novas ações. Desse modo, a escrita passa a ser uma ação que possibilita ao professor produzir um sentido pessoal sobre o seu desenvolvimento profissional, ou seja, um tipo de significado que mobiliza novas necessidades e práticas.

Além disso, descrever as atividades realizadas cotidianamente com os alunos é uma tarefa que possui um significado social dentro dos fazeres pedagógicos da docência. No cotidiano escolar, porém, o significado atribuído a essa ação de registrar pode receber um novo conceito para o professor, quando é (re)elaborado ou (re)significado por ele - que, por motivo pessoal ou necessidade - a tenha realizado. Assim, um professor pode elaborar uma descrição de seu dia de trabalho com os alunos sem problematizá-lo, ou descrever esses acontecimentos de um modo que o leve a problematizar as situações vividas, com vistas a mudanças ou ampliações de atividades para um determinado fim. Nesse caso, a ação de registrar, pertencente aos fazeres docentes, pode ser constituída como uma atividade nos moldes leontievianos (LEONTIEV, 2004). Como a profissionalidade docente é constituída coletiva e historicamente, ou seja, em um dado 
tempo histórico de produção de sentidos sobre o desenvolvimento humano, sobre o ensino, entre outras coisas, consideramos que as ações que permeiam essa prática assumirão especificidades de acordo com o meio sociocultural no qual estão inseridas.

Ao olharmos as produções escritas da estudante em foco neste artigo, tendo como referência a perspectiva da teoria da atividade, foi possível considerar que os significados sociais e/ou os sentidos pessoais puderam ser, além de mobilizados, reelaborados por ela no contexto formativo do Projeto Integrado, ao refletir em suas narrativas sobre as ações docentes que realizava na disciplina de Estágio integrada ao Projeto. Essas características de sua escrita reflexiva podem indicar, conforme a teoria, que a estudante estava em atividade.

Por outro lado, o professor pode exercer sua profissão sem produzir sentidos pessoais, não se relacionando ou modificando os significados sociais de sua ação, ou seja, sem estar em atividade (LEONTIEV, 1983, 2004). Quando isso ocorre, segundo Leontiev, ele se aliena do seu trabalho docente porque o motivo da ação não coincide com o resultado do seu trabalho.

Do mesmo modo, o estudante que frequenta a disciplina de Estágio Supervisionado no contexto do Projeto Integrado pode ou não produzir sentidos pessoais sobre sua formação para o ensino ao realizar as tarefas solicitadas (narrativas, portfólio reflexivo, adensamento teórico e projeto de ensino), desencadeando, assim, um processo de apropriação, ou não, do significado social intrínseco à sua formação inicial, lembrando que a constituição do sentido pessoal e subjetivo (GONZÁLEZ REY, 2003) relaciona-se indissociavelmente aos significados sociais das práticas vivenciadas, e que "a produção da linguagem como a da consciência e do pensamento, está diretamente misturada na origem, à atividade produtiva, à comunicação material dos homens" (LEONTIEV, 1970, p. 93).

Em analogia à ideia leontieviana de desenvolvimento psíquico, se o estudante de Licenciatura produz sentidos pessoais em processo formativo para a docência, ele mobiliza o seu próprio desenvolvimento formativo para a docência, e se há mudança no comportamento, há mudança nos processos internos de constituição de sua consciência.

\section{UM OLHAR INDICIÁRIO PARA A CONSTITUIÇÃO DOS SENTIDOS PESSOAIS PARA A DOCÊNCIA}

Para realizar a organização e análise das informações da pesquisa na qual se ancora este artigo, assumimos a proposta metodológica indiciária de Carlo Ginzburg (2003), por entendermos que essa orientação nos levaria a interpretar indícios dos sentidos pessoais de formação docente tanto nas entrevistas quanto na escrita das narrativas discentes.

O paradigma indiciário é uma proposta metodológica que tem sido utilizada com frequência nas pesquisas educacionais de vertente qualitativa - como nas investigações realizadas por Cardoso (2008), Martin (2010) e Lopretti (2013). Uma justificativa é que se trata de um modo privilegiado de observação qualitativa do fenômeno e organização 
dos eventos que o revelam. Assim, tende a ser uma metodologia que auxilia na análise dos dados da pesquisa qualitativa, posto que possibilita ao investigador compreender a historicidade constituinte do objeto investigado.

O historiador Ginzburg (2003) propõe a elaboração deste novo paradigma investigativo ao considerar que o objeto de estudo nas Ciências Humanas, ${ }^{6}$ por ser de natureza complexa - pois se constitui na relação que o homem estabelece com o conhecimento -, não pode ser estudado pela simples relação de causa e consequência ou por um processo de experimentação, como ocorre com o objeto investigado nas Ciências Naturais. Por isso, o autor defende uma metodologia de investigação que compreenda as partes que compõem a totalidade do fenômeno, dando ênfase naquilo que aparentemente não pode ser observado, mas é possível de ser significado. A linguagem é o campo de atuação desse método: o pesquisador interpreta elementos e falas possivelmente despercebidos, mas que atribuem valor ao processo de constituição do fenômeno estudado. 0 campo da linguagem em que se situa a natureza do corpus de nossa pesquisa - narrativas escritas e entrevistas - justifica a escolha do paradigma indiciário.

Encontramos uma pesquisa de doutoramento de Lopretti (2013), que também use referenciou no paradigma indiciário como metodologia de organização dos dados. Em sua investigação, a pesquisadora elucubra que essa metodologia "fundamenta-se na ideia da linguagem como elemento vivo que permite analisar e compreender o real, reconhecendo a pluralidade de sentidos que podem ser atribuídos a esse real e a possibilidade de ir além do que está exposto" (LOPRETTI, 2013, p. 186).

Assim, o pesquisador perscruta o fenômeno em estudo na tentativa de compreendê-lo pelos usos que faz de seus supostos indícios observáveis. A generalização cede lugar ao olhar sobre a singularidade do fenômeno, dada a observância de traços e pistas que compõem a realidade investigada, levando, portanto, a uma interpretação da natureza do fenômeno. Nesse sentido, considera-se que o saber indiciário é conjetural e narrativo: observam-se os sintomas, formulam-se conjecturas e constroem-se narrativas históricas para evidenciar quais indícios sustentam a existência do objeto de investigação.

O pesquisador tende a descrever aquilo que percebe como sintomas ínfimos de existência do objeto - aquilo que Ihe chama a atenção, por ser um pouco diferente do que está acostumado a ver, mas que, em sua interpretação, faz parte do que deseja investigar. Ginzburg (2003) considera que esse método trata "de formas de saber tendencialmente mudas", o que permite caracterizá-lo como a "capacidade de passar imediatamente do desconhecido para o conhecido, na base dos indícios" (p. 179). Considerando, assim, que, do mesmo modo que os pintores deixavam marcas originais em suas obras (GINZBURG, 2003), o autor de uma narrativa pode evidenciar, em sua escrita, significados e sentidos singulares sobre a experiência de formação que ali procura narrar.

Desse modo, a leitura dos materiais produzidos pelas quatro estudantes selecionadas para a pesquisa que sustenta esta discussão, foi orientada pelo modo de busca de indícios preconizado por Ginzburg (2003). Nos materiais, procuraram-se tais vestí-

\footnotetext{
${ }^{6}$ Qualquer pesquisa na área das ciências humanas irá se deter a fenômenos inerentes e produzidos nas relações sociais; portanto, observá-los é, também, considerar o aspecto histórico da trama de eventos que o constitui. 
gios em palavras e frases que pudessem expressar ou evidenciar maneiras próprias de problematizar as experiências no âmbito do Projeto Integrado e que, particularmente, evidenciassem as experiências na realização do estágio, indicando que o estudante-estagiário desenvolvia as atividades formativas (portfólio, narrativa, projeto de ensino e adensamento teórico) por um motivo relevante para sua formação como futuro professor. Considerou-se, também, que esses significados e sentidos pudessem ser sustentados por demandas pessoais anteriores ou desenvolvidas no percurso formativo do projeto.

Por isso, recorrer à leitura e interpretação dos dados relativos às narrativas e às entrevistas dos estudantes participantes do Projeto Integrado, pela organização indiciária, ofereceu elementos para uma observação conjectural da produção dos sentidos pessoais dos estudantes sobre suas trajetórias formativas no contexto do Projeto, particularmente sobre a experiência inicial como docente no âmbito do Estágio Supervisionado.

\section{O PROCESSO DE ANÁLISE DA PRODUÇÃO DE SENTIDO PESSOAL NAS NARRATIVAS REFLEXIVAS DISCENTES}

Como já dito anteriormente, para cada atividade sugerida ao estudante, no contexto formativo do Projeto Integrado - e, consequentemente, da disciplina de Estágio Supervisionado que o integrava -, havia uma intencionalidade formativa.

Antes, porém, de serem apresentadas as análises das significações dos estudantes pelas narrativas escritas, considera-se importante especificar o contexto de origem das informações da pesquisa aqui referida. Como já dito na introdução deste artigo, o contexto formativo do Projeto Integrado consistiu no conjunto de atividades propostas e desenvolvidas pelos estudantes de pedagogia que participaram do Projeto. Assim, a elaboração do portfólio e a escrita das narrativas tinham a intenção de produzir reflexões e problematizações do próprio processo de formação.

O portfólio configurar-se-ia como "a produção apoiada na seleção de eventos marcantes - isto é, de eventos, situações, episódios que melhor falassem sobre a formação de cada um -, devendo expressar aquilo que foi elaborado no encontro com as três disciplinas do Projeto" (MARTIN , 2010, p. 48). Por sua vez, as narrativas eram produzidas mensalmente ao longo do semestre letivo de ocorrência das disciplinas que compunham o Projeto Integrado. No total, eram quatro narrativas por estudante - denominadas de Narrativa 1 (N1), Narrativa 2 (N2), Narrativa 3 (N3) e Narrativa Final (NF). Essa atividade foi intencionalmente planejada pelos docentes para proporcionar aos estudantes a oportunidade de "problematizar o ofício de ensinar, fornecendo elementos para que todos os participantes da experiência didática compartilhassem dos diferentes significados atribuídos ao ato pedagógico" (MARTIN, 2010 , p. 47). Além disso, foram planejadas para oferecer um modo outro de refletir sobre as experiências docentes, que pudessem, assim, ser levadas para a vida profissional futura, para tornar visíveis as dificuldades encontradas no processo formativo do Projeto Integrado e para levar os estudantes-estagiários a estabelecerem uma relação entre teorias, estudadas no curso de Graduação, e a prática docente exercida na escola campo do estágio. 
A atividade do Seminário de Adensamento Teórico/pesquisa-ação tinha, ainda, a intenção de proporcionar aos alunos um momento de reflexão teórica e de pesquisa bibliográfica, "tendo como motivo um tema que emergisse de suas problematizações, ao observarem a rotina de ensino da sala de aula que frequentavam no campo do estágio" (MARTIN, 2010, p. 51).

Por sua vez, a atividade do Projeto de Ensino tinha a intenção de proporcionar vivências de ensino na escola - campo de realização do estágio - que possibilitassem tanto "o desenvolvimento de atividades por meio de temáticas abrangentes", como "uma discussão acerca de questões envolvidas com a prática docente, privilegiando o tratamento dos conteúdos escolares de Matemática e de Ciências, por meio de uma abordagem integradora" (AUTORA , 2010, p. 47). Se, para cada atividade, havia um objetivo de formação, em analogia à teoria da atividade de Leontiev $(1970,2004)$, pode-se afirmar que a cada uma delas era atribuído um significado social formativo pelos docentes do Projeto que as planejavam.

Para a escrita deste artigo, em específico, escolhemos a análise de excertos das narrativas 1, 2, 3 e da narrativa final da estudante P., para discutir a produção de sentido pessoal de sua formação, pois entendemos que ela demonstra claramente em sua escrita vinculações entre o contexto formativo do Projeto Integrado e sua trajetória formativa.

\section{A PRODUÇÃO DE SENTIDO PESSOAL SOBRE A PRÓPRIA FORMAÇÃ̃O DOCENTE DA ESTUDANTE ESTAGIÁRIA P.}

Em sua primeira narrativa, produzida logo após o primeiro mês de aula do semestre, P. revê a posição contrária às tarefas propostas que inicialmente havia assumido com seu grupo de trabalho, quando havia tomado como sua a fala do grupo.

Reconsiderações, murmurinhos, expectativas, negações, exposições de motivos, críticas, críticas e mais críticas. Soubemos criticar muito, tínhamos motivos, razões, afinal, organizar um projeto $X$, um portfólio e uma pesquisa-ação eram tarefas de peso considerável para estudantes do 60 semestre da Graduação. Alegávamos falta de tempo, tínhamos outros compromissos para honrar, afinal, pouco daquelas atividades auxiliariam de fato nossa formação como professores [...]. Até agora falei como parte de um grupo. Fiz dos que falaram, se expuseram, minha fala também. Estive de corpo presente nas aulas com a voz daqueles com quem eu não concordava. Mas, em meio aos escritos sinto-me à vontade o suficiente para debandar do grupo. Falarei apenas por mim, por mais que algumas pessoas em meu entorno também concordem com minha posição (P., N1).

Nesse excerto da narrativa, há indícios de mudança da adesão - "debandar do grupo" - ao significado social do grupo - "pouco daquelas atividades auxiliariam de fato nossa formação como professores" - para um sentido pessoal - "falarei por mim". Tais indícios parecem emergir do fato de a escrita da narrativa sugerir outra relação de significado com as tarefas, como podemos ver no excerto a seguir:

[a] proposta dos professores me deixou encantada. Digo isso porque no semestre passado uma das coisas mais proveitosas, prazerosas e, porque não dizer, trabalhosas, foi a confecção do portfólio. Achei extremamente rico explorar aquele 
universo de palavras, emoções, fatos e ocorridos. Pude me misturar com a teoria, perfazendo-a do meu modo, vendo sentido em pontos que somente eu, como agente ativa e passiva de meu trabalho, pude constatar. [...] Assim, fiquei satisfeita por, novamente, ser "obrigada" a fazer outro portfólio. Penso que, mesmo se não o fosse, faria só de alegria (P., N1).

Para P., uma experiência positiva com a escrita do portfólio no primeiro semestre, frequentado no âmbito do Projeto Integrado, muda o significado desta tarefa que havia construído com o grupo - o de "ser obrigada a fazer o portfólio" - para um sentido pessoal: "Penso que mesmo se não fosse obrigada a fazer (o portfólio), o faria só de alegria".

A tarefa, considerada pelo grupo de P. - e, inicialmente, também por ela - como uma ação, no sentido leontieviano, de ser movida por um motivo externo, de "ter que elaborar o portfólio", transforma-se para a aluna em uma atividade: a de realizá-la impelida por um sentido pessoal, por satisfação. Isso parece ser confirmado pelo seguinte excerto da mesma narrativa: "pude me misturar com a teoria, perfazendo-a ao meu modo, vendo sentido em pontos que somente eu, como agente ativa e passiva de meu trabalho, pude constatar". O processo de atividade, de acordo com Leontiev (2004), sempre produzirá um sentido pessoal no sujeito que o realiza, pois nele está intrínseco um motivo pessoal ou uma necessidade de realização. Já a ação propriamente dita pode ser executada sem que o sujeito produza dela um sentido pessoal.

P. narra mais uma mudança nas ações de formação, isto é, nos sentidos que atribui à realização das tarefas do Projeto Integrado. Munida de um sentido pessoal das necessidades da classe em que estagiava, abandonou o tema "Olimpíadas", escolhido pelo seu grupo, e buscou outro relacionado ao folclore, avaliado por ela como mais adequado para suprir a carência de leitura da classe. Pode-se observar uma diferença entre a primeira mudança da aluna, quando alterou seu posicionamento com relação às críticas de seu grupo às tarefas do Projeto, e esta, segundo a qual P. convence o grupo de mudar de tema, como podemos observar no excerto que segue:

Por fim, avaliando as necessidades da classe de estágio em que me encontro, achei por bem me desvencilhar do tema Olimpíadas e partir para algum que englobasse o folclore. [...] decidimos por trabalhar as obras de Monteiro Lobato, pois englobam dois aspectos deficientes nas realidades que presenciamos: a carência da dita cultura popular brasileira, seus sons, costumes, lendas, cozinhas,... bem como a defasagem na leitura (P., N1).

A estudante-estagiária oferece indícios de que produziu um sentido pessoal de sua formação por meio do estágio e do projeto de ensino ao argumentar que, neles, as ações que a motivaram dizem respeito ao seu interesse em alfabetizar os alunos por meio de um tema que lhes seja significativo - para que possam efetivamente melhorar sua capacidade de leitura -, e não por um tema preestabelecido pelo grupo e significativo somente a ele. Melhor dizendo, se o exercício docente de P. passa pela necessidade de aprendizagem efetiva dos alunos, isso indica que o motivo que a conduz se orienta por um sentido pessoal, indicativo de um desejo eficaz de formação. P. dá indícios, por- 
tanto, de que tende a assumir com significados próprios sua formação no âmbito do Projeto Integrado, orientando-se por sentido pessoal e conferindo, a esse processo, a característica de uma atividade de formação no sentido leontieviano.

Quanto ao campo de realização do estágio - a escola -, é o lugar onde P. indica, de modo enfático, aprender a ser professora e de onde passa a problematizar seus saberes de como se relacionar com os alunos que acompanha.

P. sustenta, em sua entrevista, que o sentido de satisfação, atribuído à realização das tarefas solicitadas pela disciplina de Estágio Supervisionado, deu-se em razão do fato de ela ter se dedicado com maior empenho a essa disciplina do que a todas as outras já cursadas em três anos de curso: "eu poderia ficar só com esse semestre desses três anos que passaram na faculdade, mais em relação a essa disciplina, a EP 200 (Estágio Supervisionado), porque acho que o meu empenho foi maior" (P., entrevista, dez/2008).

É interessante observar que os motivos relacionados às vivências no campo do estágio vão se (re)significando à medida que P. se envolve com o cotidiano desse contexto formativo. $\mathrm{O}$ que inicialmente a motiva nesse âmbito procede de uma necessidade pessoal de querer "letrar os alunos", que acaba se (re)significando durante o percurso tanto que as suas vivências na realização do estágio lhe renderam mais reflexões em seu diário de campo do que as produzidas na primeira narrativa relativa a outras atividades do Projeto Integrado. O fato de ela problematizar mais as suas vivências no exercício da docência do que as outras do Projeto, pode significar que está mais envolvida em seu papel de estagiária do que enquanto aluna nas outras disciplinas. Outro indício de envolvimento e constituição de um sentido pessoal formativo surge quando relembra que o seu "interesse em compreender a realidade dos alunos" se intensificou na mesma proporção em que aumentou sua vontade de ajudá-los naquilo que observou ser necessário para a formação deles, isto é: o letramento, a alfabetização dos alunos.

Minhas visitas ao estágio estão cada dia mais enriquecedoras. Percebo que meu interesse em compreender a realidade dos alunos tem aumentado consideravelmente, bem como minha vontade em ajudá-los nesse processo tão rico que é a alfabetização. Talvez minha ânsia em letrar os pequenos se deva ao fato de que algumas das atividades que meu grupo do projeto $X$ pensou levavam em conta a leitura e a escrita [...] Revisando ainda minhas anotações do diário de campo, vejo que escrevi mais perguntas reflexivas no meio das aulas do que antes da devolução da primeira narrativa (P., N2).

P. revela, também, um sentido pessoal quando relata sua tristeza por não poder comparecer à escola-campo por motivo de saúde. Em sua primeira narrativa, deixa transparecer sua expectativa sobre a realização do estágio ao relatar que se tratou de uma escolha anterior às obrigações "legais" do curso: "[...] quando muitas amigas minhas ainda estavam viajando, lá estava eu com meu diário de campo colhendo informações, recebendo desenhos, abraços, ouvindo causos e refletindo sobre como seria o próximo semestre" (P., N1). Isso indica seu interesse pela formação no campo do estágio antes mesmo de ter de cursá-lo como disciplina legalmente instituída no currículo do curso. Ao significado social da disciplina do Estágio Supervisionado (cursar mais uma disciplina do currículo do curso), P. acrescenta um sentido pessoal: o de atribuir-lhe 
maior expectativa de formação para a docência. "Confesso que fiquei um pouco triste. Não gosto de faltar aos meus compromissos - sim, enxergo o estágio como compromisso, mesmo que, teoricamente eu precisasse ir uma vez por semana na escola" (P., N3,).

No decorrer da experiência no campo de realização do estágio, a estudante-estagiária encontrou-se diante da necessidade de desenvolver a tarefa do adensamento teórico como possibilidade de aprofundar o estudo de um tema que fosse importante para compreender as vivências nesse campo de formação.

$\mathrm{O}$ grupo de $\mathrm{P}$. escolheu estudar e desenvolver o tema sobre as próprias narrativas reflexivas - o que, a princípio, não surgiu de uma necessidade da docência no estágio, mas de uma necessidade pessoal de seu grupo e dela própria de conhecer melhor essa produção. Tal escolha pode ser compreendida quando a estudante esclarece, em sua terceira narrativa, que se tratou de um tema que lhe dizia respeito, pois escrever as narrativas, como ela mesma menciona, tornou-se imprescindível e um meio de expressar as implicações semióticas de suas vivências formativas.

A importância de elaborar uma pesquisa teórica fica evidente para P. no momento em que - no decorrer do segundo mês de vivência das atividades do Projeto Integrado e, sobretudo, no que diz respeito às apresentações dos estudos teóricos no Seminário de Adensamento Teórico - desabafa que essa prática, apesar de contribuir, no seu entender, para uma melhor compreensão da realidade escolar, pareceu-lhe estar sendo "pouco aproveitada" pelos colegas. Essa necessidade de se envolver com os estudos realizados é manifestada novamente em sua última narrativa, quando lança um olhar sobre seu percurso na disciplina do Estágio Supervisionado, afirmando que gostaria de tê-la aproveitado mais. Esse anseio, porém, não se restringe a esse aproveitamento, pois $P$. revela que também gostaria de ter se envolvido mais com as orientações dos professores.

A ideia de pesquisa para incluir algo prático, real nas escolas, me parece pouco aproveitada. Não faço dessas palavras críticas, pois bem sei que eu também não compreendi todos os objetivos; só ressalto que as apresentações me pareceram apenas pesquisas e não, como proposto, pesquisas-ação (P., N2).

Acredito que minha estima por cada um deles (portfólio, aprofundamento teórico e projeto $\mathrm{X}$ ) deva-se a um motivo diverso: o primeiro por ser algo individual, único, extremamente significativo para mim, que me ajuda a enxergar com outros olhos tudo aquilo que eu vivi [...]. O aprofundamento teórico por tratar das narrativas, uma prática que muito me agrada, talvez pela minha necessidade de escrever, de falar, gritar e deixar bonito com palavras escritas, ou talvez - pode parecer besteira, mas - por ter achado um grupo que eu esteja em sintonia, já que eu, dificilmente gosto de trabalhos em grupos. [...] E, por fim o projeto $X$ por retratar de literatura, uma atividade que foi extremamente importante para minha formação como sujeito (P., N3).

[...] queria tirar mais proveito dos aprofundamentos teóricos apresentados nas tardes de segunda, ter mais tempo para conversar com os professores responsáveis pela disciplina, ser mais tolerante com minhas colegas de classe, saber me portar melhor em determinadas situações; queria me escrever mais, me contar e ser contada em uma constante relação de viver (P., NF). 
Os trechos das narrativas de P. analisados até o momento ilustram dois movimentos de representação de sentido: inicialmente, o de assumir com significado de atividade social as tarefas do Projeto Integrado; e, posteriormente, o de assumi-las com sentido pessoal, o que se evidencia quando descreve que gostaria de dar mais atenção aos alunos e de "construir uma relação de respeito mútuo" com eles, ajudando mais a professora da classe onde estagiou. A sua atuação no estágio amplia-se pela necessidade de letrar para prover mais atenção aos alunos, trabalhando em cooperação com a professora da classe onde estagia e fazendo crescer, assim, sua atuação para as questões relacionais em sala de aula. Por isso, sua necessidade vai se modificando à medida que o objeto dessa se altera, pois "[u]ma vez que a necessidade encontra a sua determinação no objeto (se "objetiva" nele), o dito objeto torna-se motivo da atividade, aquilo que o estimula" (LEONTIEV, 2004, p. 115). Entendemos que nesse contexto psicológico da atividade reside a origem do sentido pessoal.

Percebi também algumas outras mudanças em meu comportamento: comecei a indagar mais certas atitudes da professora (da sala de estágio) frente aos alunos - não apenas como uma crítica e sim para pensar em alternativas de modo que, quando eu for colocada em algumas situações vivenciadas apenas como estagiária, saiba agir diferentemente ou não da educadora; minha postura frente às manhas e caprichos das crianças - como, por exemplo, enrolar para terminar a merenda só para perder aula - tem mudado gradativamente; se antes eu era indiferente, depois mudei para a imposição por cansaço; agora tem que ser moldado na conversa, no diálogo (P., N2).

Queria dar mais atenção aos meus alunos no estágio; encontrar uma maneira de letrar algumas crianças que ainda não entendem o que escrevem, mas teimam em copiar da lousa todo o dia achando que o papel de aluno é somente esse; eu queria ajudar mais a professora, entender seus pontos, sua didática, não crucificar tanto algumas atitudes pensando que eu faria diferente no lugar dela, porque sei que ela tem boas ideais; desejava construir melhor uma relação de respeito mútuo com as crianças (P., NF).

As experiências como estagiária, no âmbito do Projeto Integrado, oportunizaram à P. o ouvir, o respeitar, o entender e o significar, em um sentido pessoal, a atuação do outro nas atividades de formação, sobretudo as do âmbito do estágio. Sem essas experiências, como menciona, não teria conseguido realizar o projeto de ensino elaborado com seu grupo. Por isso, ao reconhecer, no percurso de ser estagiária, a importância de ouvir e entender as experiências do exercício da docência na escola campo, de ouvir a professora da classe onde estagiou, as colegas e os professores supervisores do estágio, demonstra uma mudança no sentido do que é ser professora. O sentido atribuído a essa profissão modifica-se na medida em que (re)conhece suas mais diversas dimensões: afetiva, cognitiva e social. A estudante-estagiária demonstra, ainda, que aquilo que se sabe sobre ser professor, oriundo de um significado social (relação unidirecional de ensino), parece não ser mais suficiente para compreender a complexidade da profissão. 
E se não fosse nesse ouvir as experiências dos outros, se não fosse essa prática de respeitar, entender e significar realidades diversas à minha, eu não teria conseguido desenvolver o Projeto X-Projeto Integrado, não saberia me relacionar com outro alguém que não fosse eu mesma, não caberia mais a mim o papel da professora (P., NF, dez./2008).

A sua constituição como professora em formação passou inexoravelmente pela relação que estabeleceu consigo mesma e com "outro alguém" nesse percurso. Ela descreve, em sua narrativa final, uma síntese de sua percepção sobre o motivo de estar envolvida: seu anseio por compreender, narrar e refletir, pela busca da experiência que a formasse, tanto no campo de realização do estágio, quanto na organização dos projetos a serem realizados e nas profícuas relações interpessoais de cumplicidade na realização das tarefas. Mesmo, no entanto, compreendendo sua busca por "aprimoramento, fundamentação e vivências", sente que seus anseios não foram totalmente contemplados. Seu último relato desvela uma P. engajada nas tarefas que dizem respeito a sua formação profissional, assim como uma inquietude em busca de respostas, o que nos permite analisar esse envolvimento como uma significação pessoal de formação.

E estou aqui porque vivo, porque me visto de significados, porque analiso, observo [...] porque me vejo nos outros ao mesmo tempo que apreendo seus olhares em mim... é aqui que narro, que escrevo, que reflito. Nesta constante busca pelo único ato que visa à construção: a experiência. Experiência essa que tive nas aulas de Estágio Supervisionado I, nas manhãs da EMEF F.P.S., nas leituras, nas conversas por MSN com a Dani (colega do projeto X-Projeto Integrado) e nossas intermináveis madrugadas que passamos sem dormir, questionando, reformulando os projetos de ensino. [...] Apesar de querer agarrar o mundo em uma constante busca por aprimoramento, fundamentação e vivencias, não consegui possuir tudo aquilo que queria (P., NF, dez./2008).

\section{CONSIDERAÇÕES FINAIS}

A pesquisa sobre os sentidos pessoais, na perspectiva da Psicologia Histórico-Cultural, especificamente nos estudos da teoria da atividade de Leontiev (2004), indica que a estruturação de ambientes formativos que mobilizem as inter e as intra-relações com os significados sobre a prática pedagógica, pode propiciar um diferencial na formação inicial docente quando oportuniza a produção de significados, principalmente de sentidos pessoais sobre a prática docente.

O modo de olhar para a formação inicial do professor, proporcionado pela dinâmica pedagógica do Projeto Integrado - e, mais especificamente, por aquela da disciplina do Estágio Supervisionado a ele integrada -, coloca o estudante-estagiário como sujeito da própria formação. Dentre as atividades propostas, a escrita das narrativas reflexivas destaca-se como um espaço de formação que suscita o estudante a problematizar suas experiências formativas de modo a sentir-se em constante (trans)formação no contexto formativo em que está inserido.

Os sentidos pessoais produzidos pela estudante estagiária P., indiciados de suas narrativas, indicam, sob o olhar da pesquisa aqui referenciada, um movimento efetivo de formação para a docência. Ao narrar suas experiências com o estágio e com as ou- 
tras atividades do Projeto Integrado, manifesta vontade de avançar na compreensão do processo formativo do qual participa, ressignificando a obrigatoriedade das tarefas em compromissos pessoais.

Foi possível indiciar, a partir das reflexões manifestadas nas narrativas e entrevistas da estudante P., um movimento de apropriação e reelaboração dos significados do ser professora, conferindo a eles um sentido próprio, um sentido pessoal, haja vista suas expectativas e comprometimentos, anunciados, sobretudo, com as atividades do Estágio Supervisionado. Assim, a proposta de cada tarefa com significado social foi sendo redimensionada por P. em sentido pessoal, com significados de objetos de sua própria formação docente.

O que inicialmente cumpria como uma tarefa, apenas por determinação do Projeto, na escrita das narrativas, relata assumir, posteriormente, como uma necessidade pessoal. O sentido pessoal, ao mesmo tempo em que emerge da necessidade pessoal de realizar a atividade formativa sugerida, impulsiona para novas necessidades, de modo a possibilitar a estudante a ressignificar constantemente seu próprio processo formativo.

\section{REFERÊNCIAS}

ALARCÃO, Isabel. Professores reflexivos em uma escola reflexiva. 7. ed. São Paulo: Cortez, 2010.

ARAGÃO, Ana Maria Falcão; NASCIUTTI, F. M. B.; AFFONSO, B. F. Experiências na formação inicial de professores no entretecimento de teoria, prática e afetividade: contribuições da teoria histórico-cultural. In: BORUCHOVITH, E.; AZZI, R. G.; SOLIGO, Â. (org.). Temas em psicologia educacional. Contribuições para a formação de professores. Campinas: Mercado de Letras, 2017.

BAROLLI, Elisabeth; MOURA, Anna Regina Lanner; PRADO, Guilherme do Val Toledo. Narrativas na formação inicial de professores: possibilidades de articulação entre ensino e pesquisa num contexto de integração Disciplinar. In: Encontro Nacional de Didática e Prática de Ensino-Endipe, 14., 2008, Porto Alegre. Anais... Porto Alegre, 2008, p. 1-12.

BRASIL. Resolução no 2, de 26 de junho de 1997. Dispõe sobre os programas especiais de formação pedagógica de docentes para as disciplinas do currículo do Ensino Fundamental, do Ensino Médio e da educação profissional em nível médio. Disponível em: . Acesso em: mar. 2016.

BRASIL. Portaria no 1.087, de 10 de agosto de 2011. Institui a Rede Nacional de Formação Continuada dos Profissionais do Magistério da Educação Básica Pública. Ministério da Educação. Disponível em: . Acesso em: mar. 2016.

BRASIL. Decreto no 8.752, 9 de maio de 2016. Dispõe sobre a Política Nacional de Formação de Profissionais da Educação Básica. Disponível em: http://www.planalto.gov.br/ccivil_03/_Ato2015-2018/2016/ Decreto/D8752.htm\#art19. Acesso em: ago. 2016.

CARDOSO, Virgínia Cardia. A cigarra e a formiga: uma reflexão sobre a educação matemática brasileira da primeira década do séc XXI. 2008. 209 f. Tese (Doutorado em Educação) - Faculdade de Educação, Universidade Estadual de Campinas, Campinas, 2008.

GINZBURG, Carlo. Mitos, emblemas, sinais: morfologia e história. Tradução Frederico Carotti. São Paulo: Companhia das Letras, 2003.

GONZÁLEZ REY, Fernando. Sujeito e subjetividade: uma aproximação histórico cultural. Tradução Raquel Souza Lobo Guzzo. São Paulo: Pioneira Thomson Learning, 2003.

GUEDES-PINTO, Ana Lúcia.; FONTANA, Roseli Aparecida Cação. Apontamentos teórico-metodológicos sobre a prática de ensino na formação inicial. Educação em Revista, Belo Horizonte, n. 44, p. 69-87, dez. 2006. Disponível em: http://www.scielo.br/pdf/edur/n44/a04n44.pdf. Acesso em: mar. 2016.

LEONTIEV, Alexei. N. Linguagem e razão humana. Enciclopédia do Homem contemporâneo. Tradução Conceição Jardim e Eduardo Lúcio Nogueira. Lisboa: Editorial Presença, 1970.

LEONTIEV, Alexei. Actividad, consciência, personalidad. 2. ed. Habana: Editorial Pueblo y Educación, 1983. LEONTIEV, Alexei. O desenvolvimento do psiquismo. 2. ed. Tradução Rubens Eduardo Frias. São Paulo: Centauro, 2004. 
LOPRETTI, Tamara Abrão Pino. E os saberes das crianças ensinam à professora: contribuições para o desenvolvimento pessoal e profissional docente. 2013, 307f. Tese (Doutorado em Educação) - Programa de Pós-Graduação em Educação, Universidade Estadual de Campinas, Campinas, 2013.

MARTIN, Adriana Ofretorio de Oliveira. Significados e Sentidos sobre os processos formativos de estudantes de Pedagogia. 2010. 153 f. Dissertação (Mestrado em Educação) - Faculdade de Educação, Universidade Estadual de Campinas, Campinas, 2010.

MARTINS, André Ferrer P. Estágio supervisionado em física: o pulso ainda pulsa... Revista Brasileira de Ensino de Física, São Paulo, v. 31, n. 3, p. 3.402.1-3.402.7, set./2009. Disponível em: http://www.scielo.br/ scielo.php?script=sci_arttext\&pid=S1806-11172009000300006\&lng=en\&nrm=iso\&tlng=pt. Acesso em: 10 mar. 2016.

NAKAMURA. Érika Mitsue. Problematização indisciplinar de práticas socioculturais na formação inicial de professores. 2014. Dissertação (Mestrado em Educação) - Programa de Pós-Graduação Multiunidades em Ensino, Universidade Estadual de Campinas, Campinas, 2014.

PIMENTA, Selma Garrido. Saberes pedagógicos e atividade docente. 3. ed. São Paulo: Cortez, 2002.

PIMENTA, Selma Garrido. Professor reflexivo: construindo uma crítica. In: PIMETNA, S. G.; GHEDIN, E. (org.). Professor reflexivo no Brasil. Gênese e crítica de um conceito. 2. ed. São Paulo: Cortez, 2008.

PIMENTA, Selma Garrido.; GHEDIN, E. (org.). Professor reflexivo no Brasil. Gênese e crítica de um conceito. 2. ed. São Paulo: Cortez, 2008.

PIMENTA, Selma Garrido.; LIMA, M. S. L. Estágio e docência. 6. ed. São Paulo: Cortez, 2011.

PIMENTA, Selma Garrido. Os (des)caminhos das políticas de formação de professores - o caso dos estágios supervisionados e o programa de iniciação à docência: duas faces da mesma moeda? REUNIÃO NACIONAL DA ANPEd, 38., 2017, São Luís, MA: Ufma, 10 a 5 de outubro de 2017. Disponível em: http://38reuniao.anped.org.br/sites/default/files/resources/programacao/sessoes_38anped_2017_3_politicas_educacionais_em_disputa_ima_garrido_socorro.pdf. Acesso em: 11 jul. 2019.

PRADO, Guilherme do Val Toledo; FERREIRA, Claudia Roberta; FERNANDES, Carla Helena. Narrativas pedagógicas e memoriais de formação: escrita dos profissionais da educação. Revista Teias, Uerj (on-line), v. 12, p. 143-153, 2011. Disponível em: https://www.e-publicacoes.uerj.br/index.php/revistateias/article/ view/24216. Acesso em: set. 2012.

SÁ-CHAVES, Idália. Portfólios reflexivos: estratégia de formação e supervisão. 2. ed. Aveiro: Universidade, 2004.

SCHÖN, Donald. Educando o profissional reflexivo: um novo design para o ensino e a aprendizagem. Tradução Roberto Cataldo Costa. Porto Alegre: Artmed, 2000.

UNTALER, Lindomar de Oliveira. Aproximações de estudantes de um curso de pedagogia com a temática ambiental. 2011, 82 f. Dissertação (Mestrado) - Universidade Estadual de Campinas, Faculdade de Educação, Campinas, São Paulo. Disponível em: http://repositorio.unicamp.br/handle/REPOSIP/251266. Acesso em: 18 ago. 2018.

VYGOTSKY, Lev Semyonovich. Pensamento e linguagem. Tradução Jefferson Luiz Camargo. 4. ed. São Paulo: Martins Fontes, 2008.

ZABALZA, Miguel A. O estágio e as práticas em contextos profissionais na formação universitária. 1. ed. São Paulo: Cortez, 2014.

ZEICHNER, Kenneth. A formação reflexiva de professores: idéias e práticas. Lisboa: Educa, 1993.

ZEICHNER, Kenneth Uma análise crítica sobre a "reflexão" como conceito estruturante na formação docente. Educ. Soc., Campinas, v. 29, n. 103, p. 535-554, maio/ago. 2008. Disponível em: http://www.scielo. br/pdf/ es/ v29n103/12.pdf. Acesso em: set. 2009. 